\title{
Exame de Papanicolaou: Qualidade do Esfregaço Realizado por Alunos de Enfermagem ${ }^{1}$ \\ Papanicolaou Test: Quality of Smear Performed by Nursing Students
}

\author{
Marilia Leonardo dos Santos ${ }^{2}$, Mirian Soriano Moreno ${ }^{2}$, Valdina Marins Pereira ${ }^{3}$
}

\section{Resumo}

O câncer cervical é prevenível ou curável quando detectado precocemente, porém o impacto sobre a morbimortalidade por essa doença depende não só da disponibilidade e cobertura do exame preventivo, como também da qualidade da amostra colhida. A negligência neste último aspecto pode ocasionar resultados falso-negativos e retardar o diagnóstico e o tratamento. O objetivo deste estudo foi avaliar o esfregaço de Papanicolaou realizado por alunos de enfermagem, comparando-o ao material colhido por profissionais. Cento e doze esfregaços foram analisados em um mesmo laboratório, sendo 56 colhidos por alunos e 56 colhidos por profissionais (grupo-controle), nas mesmas Unidades de Saúde e no mesmo período de tempo. A análise constatou um número de amostras insatisfatórias acima do aceitável, porém, no grupo-controle, esse percentual foi significantemente maior do que no grupo em estudo, para as mulheres com 40 anos ou mais. A ausência de representatividade da junção escamo-colunar (JEC) foi a causa prevalente da classificação da amostra como insatisfatória. Os autores recomendam a revisão dos procedimentos de coleta e a repetição desta sempre que a JEC não estiver devidamente representada no esfregaço.

Palavras-chave: Esfregaço vaginal; Prevenção de câncer de colo uterino; Controle de qualidade

${ }^{1}$ Pesquisa realizada com uma bolsa de Iniciação Científica do CNPq

${ }^{2}$ Alunas da $4^{\mathrm{a}}$ série do Curso de Enfermagem da PUC-SP - Sorocaba (SP)

${ }^{3}$ Prof. a Associada do Depto. de Enfermagem/Disciplina Enfermagem na Reprodução Humana. Orientadora. Centro de Ciências Médicas e Biológicas de Sorocaba. FCM. PUC-SP.

Endereço para correspondência: Valdina Marins. Rua Cel. José Pedro de Oliveira, 412 - Jardim Faculdade - Sorocaba (SP), Brasil. E-mail: facaval@terra.com.br 


\section{INTRODUÇÃO}

Embora o câncer cervical seja uma patologia com enorme potencial de prevenção e cura, estima-se que, nos países em desenvolvimento, apenas $49 \%$ das mulheres que o adquirem sobrevivem além de cinco anos. Em países desenvolvidos, onde o diagnóstico é realizado precocemente, a cura chega a quase $70 \%$ das portadoras ${ }^{1}$.

A evolução de uma lesão de baixo grau para um carcinoma invasivo pode levar 10 a 15 anos $^{2}$. É tempo suficiente para uma intervenção que poderá mudar o curso da vida da mulher. $\mathrm{O}$ estudo pioneiro, realizado por Georg Papanikolaou ${ }^{3}$ na década de 1930, resultou em um procedimento que possibilitou a descoberta de lesōes precursoras dez anos antes da manifestação do câncer propriamente dito no tecido cervical.

Em 1998, o Ministério da Saúde do Brasil estabeleceu que o teste de Papanicolaou (PAP) deve ser realizado anualmente por mulheres com idade entre 25 e 60 anos ou antes desta faixa etária, caso já tenham mantido relaçôes sexuais ${ }^{4}$.

Entretanto, para que o teste de Papanicolaou tenha um resultado confiável, são preconizados alguns requisitos indicados no documento publicado pela Fundação Oncocentro (FOSP) e Secretaria da Saúde do Estado de São Pauló .

O Sistema Bethesda (TBS), documento apresentado por um grupo de citologistas, histologistas e terapeutas em oncologia, introduziu a análise da qualidade do esfregaço no laudo do exame citopatológico, levando em conta os componentes presentes na amostra ${ }^{4}$. O mesmo grupo, em 2001, propôs modificaçōes no documento anterior, publicando o TBS para Citologia Cervicovaginal 5 .

A Organização Mundial da Saúde (OMS), com base em estudos epidemiológicos, demonstrou que mulheres com resultados normais ou apenas alterações benignas no exame de PAP, em dois exames consecutivos (anuais), podem repeti-los em intervalos de três anos, porém se os procedimentos de coleta não forem condizentes com as normas preconizadas, o risco de exposição à doença não será minimizado. Os índices de resultados falsonegativos são alarmantes ${ }^{6}$, levando ao retardo do tratamento e piora do prognóstico em grande número de mulheres ${ }^{7}$.

A confiabilidade do exame depende de dois fatores: os relacionados à coleta e os relacionados aos procedimentos laboratoriais. Neste estudo, focalizouse o fator relacionado à coleta.

O interesse pelo tema surgiu da preocupação com a confiabilidade dos resultados de amostras colhidas por alunos do terceiro ano de enfermagem, os quais realizam este procedimento, rotineiramente, no estágio da disciplina Enfermagem na Reprodução Humana, em Unidades Básicas de Saúde (UBSs) de Sorocaba.

Embora simples de ser executado, para se obter um resultado final que assegure à mulher a inexistência de qualquer lesão neoplásica ou precursora na cérvix, o aluno deve ter bom conhecimento anatômico para localizar a cérvix e discernir os epitélios cervicais (ecto e endocervix), ter destreza para manusear a espátula de Ayre e a escova endocervical e para realizar o esfregaço, fixando-o no tempo mais curto possível de forma a preservar as células.

Para quem está realizando a coleta pela primeira vez, não é uma tarefa fácil. Entretanto, é fundamental que a situação de aprendizado não redunde em prejuízo à mulher assistida, expondo-a a um índice de resultados falso-negativos acima do aceitável. Em 1998, durante o Programa Nacional de Combate ao Câncer de Colo do Útero, foram revistas 2.278 lâminas colhidas em Naviraí/MS, e encontrados $12,5 \%$ de esfregaços insatisfatórios. Esse número foi considerado elevado ${ }^{8}$.

O objetivo deste estudo foi verificar a qualidade do esfregaço de material cervical para teste de Papanicolaou realizado por alunos do terceiro ano do Curso de Enfermagem da PUC-SP em relação a um grupocontrole, considerando-se os parâmetros estabelecidos no documento da Fundação Oncocentro (FOSP) e Secretaria de Saúde do Estado de São Pauló .

\section{METODOLOGIA}

O estudo foi desenvolvido no campus Sorocaba da PUC-SP e a casuística foi constituída por exames preventivos de câncer cervical de mulheres atendidas em duas Unidades Básicas de Saúde de Sorocaba, no período de maio de 2006 a maio de 2007.

O grupo de estudo foi composto de 56 exames citopatológicos, cujos esfregaços para o teste de Papanicolaou foram colhidos por alunos do terceiro ano de enfermagem, no estágio curricular, sob supervisão da docente da disciplina. Para o grupo-controle, foram escolhidos, aleatoriamente, 56 esfregaços que haviam sido realizados por profissionais, nas mesmas Unidades de Saúde, no mesmo período de tempo.

Todos os esfregaços incluídos no estudo foram analisados por uma única médica citologista, no laboratório que faz a leitura oncocitológica das amostras efetuadas pelas UBSs envolvidas.

Foram critérios de inclusão: idade igual ou superior a 14 anos; vida sexual ativa ou que já tivesse iniciado vida sexual; ausência de doença ginecológica no 
momento da coleta; último exame de Papanicolaou com resultado normal ou estivesse realizando esse exame pela primeira vez.

A qualidade da amostra foi avaliada segundo os critérios estabelecidos no Manual de Procedimentos Técnicos e Administrativos da Fundação Oncocentro de São Paulo ${ }^{4}$, modificados para este estudo, como explicitado a seguir.

Segundo o documento citado, após a análise oncocitológica, a amostra pode ser classificada como: satisfatória ou insatisfatória. É considerada amostra insatisfatória quando a leitura for prejudicada por:

- Deficiência do número de células ( $<10 \%$ do esfregaço).

- Leitura prejudicada por presença, em mais de $75 \%$ do esfregaço, de:

- Sangue

- Piócitos

- Artefatos de dessecamento

- Contaminantes externos

- Intensa superposição celular

Nesta condição, o laudo volta à unidade de origem, indicando-se a razão da classificação, com orientação para se fazer nova coleta.

Por sua vez, o manual considera amostra satisfatória quando o esfregaço contém "[...] células em quantidade representativa, bem distribuídas, fixadas e coradas, de tal modo que sua visualização permita uma conclusão diagnóstica ${ }^{4}$ " Não se exige, para esta classificação, a presença de células de ambos os epitélios cervicais: escamoso e endocervical e/ou metáplasico, porém o laboratório deve apontar, em lugar apropriado do impresso de requisição $\left({ }^{*}\right)$, quais os epitélios representados no esfregaço, cabendo ao profissional responsável pela entrega do resultado decidir a conduta adequada.

Contudo, o citado documento, logo em seguida assevera $[\ldots]$

A presença de células metaplásicas ou células endocervicais, representativas da junção escamo-colunar (JEC), tem sido considerada como indicador de qualidade do exame, pelo fato de as mesmas se originarem do local onde se situa a quase totalidade dos cânceres de úteró ${ }^{4}$.

Donde se pode inferir que a classificação de amostra satisfatória a um esfregaço que não tenha representatividade da JEC estaria expondo a mulher a um resultado falso-negativo. Por esse motivo, neste estudo, além dos critérios anteriormente expostos, só foram designadas como satisfatória as amostras que apresentaram células do epitélio escamoso e do epitélio endocervical e/ou metaplásico.

A variável utilizada para comparar a qualidade dos esfregaços colhidos por alunos em confronto com o grupo-controle foi o número de amostras classificadas como insatisfatórias na análise laboratorial, observandose o parâmetro acima descrito.

A preocupação inicial dos autores deste trabalho era de que os esfregaços realizados pelos alunos apresentassem uma proporção de esfregaços insatisfatórios maior do que a encontrada no grupo-controle, considerando-se que a maioria dos alunos estava realizando o procedimento de coleta pela primeira vez.

Com o objetivo de homogeneizar os grupos em estudo, foi realizado o pareamento quanto a duas variáveis consideradas relevantes: idade e fase da vida em que se encontrava a mulher na ocasião do exame, se menopausada ou não ${ }^{9}$. Essas duas variáveis foram escolhidas por determinarem alteraçôes na cérvix e na localização da JEC.

O estudo foi aprovado pelo Comitê de Ética do Centro de Ciências Médicas e Biológicas de Sorocaba, campus da PUC-SP, onde se realizou a pesquisa.

Às mulheres que se submeteram ao exame realizado por alunos, foram solicitadas a leitura e assinatura do Termo de Consentimento antes da coleta; porém os esfregaços obtidos para o grupo-controle foram escolhidos aleatoriamente, após as colheitas terem sido realizadas. $\mathrm{O}$ uso desses resultados para fins do estudo não implicou nenhuma alteração nos procedimentos de rotina do exame de Papanicolaou. Os profissionais, cujas amostras constituíram este grupo, não foram identificados, por razōes éticas.

\section{RESULTADOS E DISCUSSÃO}

Participaram da casuística mulheres de 14 a 78 anos, predominando a faixa etária entre 20 e 50 anos. Quanto à paridade, predominaram mulheres com um a quatro filhos; a maioria das participantes $(89 \%$ no grupo em estudo e $83 \%$ no grupo-controle) havia realizado Papanicolaou anteriormente.

Observou-se que o número de multíparas foi maior em ambos os grupos. Lembrando-se a vulnerabilidade maior para o câncer cervical nestes casos, há que considerar a grande responsabilidade de se obter amostras de boa qualidade nessas mulheres. 
Por deficiência no preenchimento das requisições no grupo-controle, não foi possível tabular o número de gestaçōes de todas as mulheres estudadas. Entretanto, foi significativo o número de abortamentos relatados em ambos os grupos: 9 no grupo de alunos $(16,1 \%)$ e 9 no grupo-controle $(28,1 \%$ das 32 mulheres, cuja informação constava do prontuário).

Das mulheres que haviam feito o exame de Papanicolaou anteriormente, 58 mulheres o haviam feito há três anos ou menos, constatando-se uma cobertura de $73,4 \%$ das 79 mulheres que informaram este dado. Essa cobertura é maior do que a encontrada no Inquérito Domiciliar realizado pelo Ministério da Saúde em 15 capitais e no Distrito Federal ${ }^{1}$, que mostrou uma variação de $33 \%$ a $64 \%$ nas mulheres atendidas pelo Sistema Único de Saúde (SUS). Cobertura mais eficiente registrada em Londrina-PR e região ${ }^{10}$, onde o número de mulheres que havia feito o Papanicolaou nos últimos três anos variou de $71,5 \%$ a $88,4 \%$. Em Sorocaba, em $1997^{11}$, foram entrevistadas 356 mulheres de 17 a 84 anos, constatando-se que $65,7 \%$ haviam feito seu exame preventivo há menos de dois anos.

Outras informaçôes que poderiam também influenciar nas condições da cérvix, como, por exemplo, o uso de hormônios, a idade do primeiro coito e a história de sangramento pós-coital, não constavam da grande maioria das requisições (impresso 415), inviabilizando a apreciação destes dados.

Como previsto na Metodologia, os grupos foram pareados com relação a duas variáveis: a faixa etária e a situação da mulher, se menopausada ou não, na ocasião do exame.
A distribuição das mulheres com relação à menopausa não demonstrou diferença significante entre os grupos estudados (tabela 1).

O pareamento com relação ao grupo etário mostrou diferença significante entre os grupos $\left(x^{2}=12,44 ; p>0,02\right)$; por esse motivo, foram cotejados, em separado, os esfregaços de mulheres com menos de 40 anos e, por sua vez, os esfregaços de mulheres de 40 anos e mais.

O número de amostras insatisfatórias de mulheres com menos de 40 anos foi de $15,4 \%$ entre as colhidas por alunos e 19,3\% no grupo-controle (Tabela 2), não sendo estatisticamente significante essa diferença $\left(\mathrm{x}^{2}=3,84, \mathrm{p}<0,02\right)$.

Quando se comparou, porém, o número de amostras insatisfatórias colhidas em mulheres de 40 anos e mais, entre os dois grupos estudados, (tabela 3) a análise estatística mostrou um número significantemente maior entre os profissionais $(37,5 \%$ contra $5,6 \%$ entre os alunos). Como já foi mencionado, existe certa dificuldade em se obter células endocervicais e/ou da junção escamo-colunar nessa faixa etária em virtude do entrópio da JEC, que ocorre na maioria dessas mulheres. Para que se garanta a representatividade da endocérvix, é imprescindível que se utilize, neste caso, a escova endocervical ou citobrush ${ }^{12}$.

A causa predominante de insatisfatoriedade, para ambos os grupos, foi a ausência de células endocervicais e metaplásicas, ou seja, as células da JEC não estavam aqui representadas (Tabela 4). A rigor, estas coletas deveriam ser refeitas sob pena de a mulher não ter um resultado fidedigno do seu exame.

Tabela 1. Número de mulheres menopausadas segundo o grupo estudado (alunos e profissionais)

\begin{tabular}{l|c|c|c|c}
\hline & \multicolumn{3}{|c|}{ Alunos } & \multicolumn{2}{c}{ Profissionais } \\
\cline { 2 - 5 } & $\mathbf{n}$ & $\%$ & $\mathbf{n}$ & 16,7 \\
\hline Menopausadas & 12 & 21,4 & 9 & 83,3 \\
\hline Não-menopausadas & 44 & 78,6 & 45 & 100,0 \\
\hline Total & 56 & 100,0 & $54^{*}$ & \\
\hline
\end{tabular}

$\mathrm{X}^{2}$ calculado $=0,40 \quad(\mathrm{P}<0,02)$

* Dado não informado em dois casos

Tabela 2. Amostras satisfatórias e insatisfatórias realizadas por alunos e profissionais em mulheres com menos de 40 anos

\begin{tabular}{l|c|c|c|c}
\multicolumn{1}{c|}{ Grupos } & Satisfatórias & Insatisfatórias & Total & $\%$ de Insatisf. \\
\hline Alunos & 33 & 6 & 39 & 15,4 \\
\hline Profissionais & 25 & 6 & $31^{*}$ & 19,3 \\
\hline Total & 58 & 12 & 70 & - \\
\hline
\end{tabular}

$\mathrm{X}^{2}$ calculado $=0,19$

$\mathrm{X}^{2}$ crítico=3,84 não significante

*Dado não informado em um caso 
Tabela 3. Amostras satisfatórias e insatisfatórias realizadas por alunos e profissionais em mulheres com 40 anos ou mais

\begin{tabular}{l|c|c|c|c}
\multicolumn{1}{c|}{ Grupos } & Satisfatórias & Insatisfatórias & Total & $\begin{array}{c}\% \text { de } \\
\text { Insatisfatórias }\end{array}$ \\
\hline Alunos & 16 & 1 & 17 & 5,9 \\
\hline Profissionais & 15 & 8 & $23^{*}$ & 34,8 \\
\hline Total & 31 & 9 & 40 & - \\
\hline
\end{tabular}

Teste exato de Fisher $\mathrm{P}=0,0335$ significante

*Dado não informado em um caso

Tabela 4. Resultados encontrados nas amostras insatisfatórias em ambos os grupos estudados

\begin{tabular}{l|c|c}
\hline \multicolumn{2}{|c}{$\mathbf{n}$} & $\%$ \\
\hline \multicolumn{1}{|l}{ ALUNOS } & \multicolumn{1}{l}{} \\
\hline $\begin{array}{l}\text { Ausência de células endocervicais e } \\
\text { de células metaplásicas }\end{array}$ & 7 & 100 \\
\hline Presença de sangue & 0 & - \\
\hline Total de amostras insatisfatórias & 7 & 100 \\
\hline PROFISSIONAIS & & \\
\hline $\begin{array}{l}\text { Ausência de células endocervicais e } \\
\text { de células metaplásicas }\end{array}$ & 14 & 93 \\
\hline Presença de sangue & 1 & 7 \\
\hline Total de amostras insatisfatórias & 15 & 100 \\
\hline
\end{tabular}

Duas possibilidades podem ter ocorrido: a supressão da colheita endocervical ou a obtenção de material de local inadequado. Esta última razão pode explicar a ocorrência no grupo de alunos, lembrando que a maioria destes estavam realizando a coleta pela primeira vez.

Considerando-se como aceitável a ocorrência de até $10 \%$ de esfregaços insatisfatórios ${ }^{8}$, este estudo indica que há necessidade de revisão do processo de colheita para que seja assegurado às mulheres assistidas o direito ao diagnóstico e conduta adequados quanto ao exame preventivo do câncer cervical.

É válido lembrar que o procedimento de prevenção do câncer cervical expóe a mulher a constrangimentos de menor ou maior intensidade, dependendo da idade e da personalidade de cada uma. A confiabilidade do resultado viria compensar esses desconfortos ${ }^{13}$.

A classificação das amostras utilizadas neste trabalho foi condizente com o princípio de que o câncer cervical - em 93\% dos casos - se inicia na intersecção dos dois epitélios que revestem a cérvix ${ }^{14}$, o que equivale dizer que não pode ser assegurada à mulher a ausência de lesões precursoras de câncer cervical quando a JEC não estiver representada no esfregaço.

Vale ressaltar que o sistema aplicado na rede pública atualmente não obriga a representatividade dos dois epitélios cervicais para a denominação de amostra satisfatória, ficando a cargo dos profissionais responsáveis pela entrega do resultado a decisão de repetição ou não da coleta, dependendo das condições específicas de cada mulher. Estaria esse profissional consciente dessa função e de sua responsabilidade?

A questão da qualidade da amostra torna-se ainda mais relevante com a atual orientação de ampliar o período entre os exames para três anos, porém deve-se estar atento que o documento da $\mathrm{FOSP}^{4}$ destaca como requisito a exigência de representatividade da JEC (p.15) nos dois exames anteriores. Apenas dessa forma a proteção da mulher estaria garantida.

\section{RECOMENDAÇÕES}

Uma das maiores dificuldades encontradas neste estudo foi o preenchimento incompleto das requisiçōes de Papanicolaou, com ausência de dados fundamentais, como, por exemplo, idade da mulher e dados ginecoobstétricos. Este fato já foi apontado em outros trabalhos $^{15,16}$. O problema dos registros de ações praticadas por alguns profissionais de saúde é endêmico e é consequência, talvez, de deficiências na formação e/ ou atualização, corroborada pela ausência absoluta de controle e punição na maioria das instituiçôes públicas. Não se enfatiza, suficientemente, que o registro da assistência prestada é direito da paciente. $\mathrm{O}$ processo terapêutico só poderá ser adequado se houver coerência entre as etapas, e a evolução desse processo só é possível se os prontuários forem adequadamente preenchidos.

O documento publicado pelo Ministério da Saúde em $2006^{1}$ aponta como uma das causas da prevalência do diagnóstico tardio do câncer cervical, em muitas regiōes brasileiras, "a baixa capacitação dos recursos humanos envolvidos na atenção oncológica...". Essas falhas, no caso específico do exame de Papanicolaou, além de inviabilizar pesquisas, fatalmente causarão prejuízos à qualidade do screening, impossibilitando a correlação dos achados laboratoriais com os dados clínicos, correlação essa que se faz necessária para diagnóstico e conduta acertados para cada mulher ${ }^{5}$.

Pouco pode ser feito no laboratório, em termos de redução de resultados falso-negativos, quando uma lesão 
no colo não está representada na amostra enviada ${ }^{17}$. Franco et al. ${ }^{18}$ sugerem que os laboratórios de citopatologia emitam, periodicamente, relatório dos exames realizados para cada profissional que o realiza. Se, repetidamente, a qualidade amostral for deficiente, deveriam ser fornecidas orientaçōes direcionadas a esses profissionais para que o procedimento de coleta fosse revisto.

$\mathrm{Na}$ realidade, os profissionais de saúde devem ir além de um exame tecnicamente bem feito; devem cumprir também seu papel educativo para propiciar a mudança de comportamento da população em relação ao câncer ${ }^{19,20}$.

Sugere-se que sejam realizadas pesquisas no sentido de verificar qual a conduta tomada frente à mulher, na rotina diária das UBSs, quando os laudos laboratoriais indicam a ausência de células da JEC, pois é precisamente neste local que se iniciam 93\% dos cânceres cérvico-uterinos.

A conscientização dos profissionais envolvidos nas ações de rastreamento do câncer cervical é condição sine qua non para que os diagnósticos citopatológicos possam ser fidedignos e o número de resultados falsonegativos seja minimizado. A intenção dos autores deste trabalho foi também a de provocar reflexão sobre este tema, lembrando a responsabilidade dos profissionais que atuam na assistência à mulher para a mudança do perfil epidemiológico do câncer cervical em nosso país.

\section{AGRADECIMENTOS}

Os autores expressam os agradecimentos ao Conselho Nacional de Desenvolvimento Científico e Tecnológico (CNPq), pela concessão da Bolsa de iniciação científica à aluna Marília Leonardo dos Santos, coautora do estudo; à Dra. Selma Pedroso Lippi, pela leitura de todas as lâminas incluídas no estudo, bem como pelas orientaçōes valiosas; ao Prof. Dr. Neil Ferreira Novo, pela análise estatística dos dados coletados.

\section{Declaração de conflito de interesses: nada a declarar.}

\section{REFERÊNCIAS}

1. Instituto Nacional de Câncer. Nomenclatura brasileira para laudos cervicais e condutas preconizadas: recomendaçōes para profissionais de saúde. Rev Bras Cancerol. 2006;52(3):213-36.

2. Instituto Nacional de Câncer. Viva Mulher - Programa de Nacional de Controle do Câncer do Colo do Útero e de Mama. Câncer do colo do útero: informaçōes técnico gerenciais e açōes desenvolvodas. Rio de Janeiro (Brasil): Instituto Nacional de Câncer; 2002.
3. Louros N. George papanicolau. Matern infanc. (São Paulo). 1962:337-40. Tradução de J. Clemente de Almeida Moura.

4. São Paulo (Estado). Secretaria da Saúde do Estado de São Paulo. Fundação Oncocentro de São Paulo. Condutas clínicas frente aos resultados do exame de Papanicolaou. 2a ed. São Paulo: Fundação Oncocentro de São Paulo; 2006.

5. Solomon D, Nayar R. Sistema Bethesda para citopatlogia cervicovaginal: definições, critérios e notas explicativas. 2a ed. Rio de Janeiro: Revinter; 2005.

6. Alves ALL, Almeida GM, Melo VHD. Qualidade da amostra colpocitológica. Femina. 2002;30(3):157-62.

7. Queiroz C. Resultados falso-negativos na citologia cervical: causas e como evitar. Femina. 2001;29(4):211-17.

8. Neto AR, Ribalta JCL, Focchi J, Baracat EC. Avaliação dos métodos empregados no Programa Nacional de Combate ao Câncer do Colo Uterino do Ministério da Saúde. Rev Bras Ginecol Obstet. 2001;23(4):209-15.

9. Siegel S, Castellan Jr NJ. Nonparametric statistics. 2a ed. New York: MacGraw-Hill; 1988.

10. Silva DW, Andrade SN, Soares DA, Turini B, Scnechk CA, Lopes MLS. Cobertura e fatores associados com a realização do exame Papanicolaou em município do sul do Brasil. Rev Bras Ginecol Obstet. 2006;28(1):24-31.

11. Bertolaccini MIBC, Pereira VM. Conhecimento e práticas da população feminina de Sorocaba referentes ao exame preventivo do câncer cervical (1997). Rev Paul de Enferm. 2001;20(1):34-41.

12. Arbyn M, Herbert A, Schenck U, Nieminen P, Jordan J, Mcgoogan E, et al. European guidelines for quality assurance in cervical cancer screening: recommendations for collecting samples for conventional and liquid-based cytology. Cytopathology. 2007;18(3):133-9.

13. Greenwood AS, Machado MFAS, Sampaio MMV. Motivos que levam mulheres a não retornarem para receber o resultado de exame Papanicolaou. Rev Latino-Am Enfermagem. 2006;14(4):503-9.

14. Pschyrembel W. Ginecologia prática. Rio de Janeiro: Guanabara Koogan; 1975.

15. Pittoli JE, Mello ES, Pereira SMM, Maeda MYS, Utagawa ML, Celestino JD, et al. Revisão de esfregaços cervicais negativos em pacientes com lesões intra-epiteliais de alto grau. J Bras Patol Med Lab. 2003;39(3):219-21.

16. Amaral RG, Ribeiro AA, Miranda FA, Tavares SBN, Souza NLA, Manrique EJC, et al. Fatores que podem comprometer a qualidade dos exames citopatológicos no rastreamento do câncer do colo do útero. Rer Bras Anal Clin. 2006;38(1):3-6.

17. Carvalho NS, Piazza MJ, Collaço LM, Chuery ACS, Utida GM, Schwarz R, et al. Citologia oncótica: qual a metodologia ideal de coleta? Femina. 2002;30(1):9-12.

18. Franco R, Amaral RG, Montemor EBL, Montis DM, Moraes SS, Zeferino LC. Fatores associados a resultados falso-negativos de exames citopatológicos do colo uterino. Rev Bras Ginecol Obstet. 2006;28(8):479-85.

19. Carvalho EC, Tonani M, Barbosa JS. Ações de enfermagem para combate ao câncer desenvolvidas em Unidades Básicas 
de Saúde de um município do Estado de São Paulo. Rev Bras Cancerol. 2005;51(4):297-303.
20. Netto AR, Ribalta JCL, Focchi J. A dimensão da prevenção e o câncer do colo uterino. Femina. 2006;34(2):87-9.

\section{Abstract}

Cervical cancer is prevented or healed if detected early but its impact on morbimortality depends upon not only the availability and coverage of the preventive test, but also the smear quality. The negligence on the latter can bring about false-negatives results, delaying its diagnosis and treatment. The aim of this study is to evaluate the Papanicolaou smear performed by nursing students and make a comparison with the Pap smears made by health care professionals. A hundred and twelve smears were analyzed in the same laboratory, fifty six of them performed by students and 56 by professionals (control group), collected in the same Health Unities and during the same period of time. The analysis showed a number of dissatisfactory smears higher than acceptable on the whole. However, in the control group, this percentage was significantly higher than those found in the study group, for the forty-year old women or elder. The absence of squamous-columnar junction's cells (SCJ) in the smear samples was the main cause of dissatisfaction. The authors recommend the revision of collection procedures and the repetition of a new collect whenever the SCJ cells were not appropriately visible in the smear.

Key words: Vaginal smears; Cervix neoplasms prevention; Quality control 